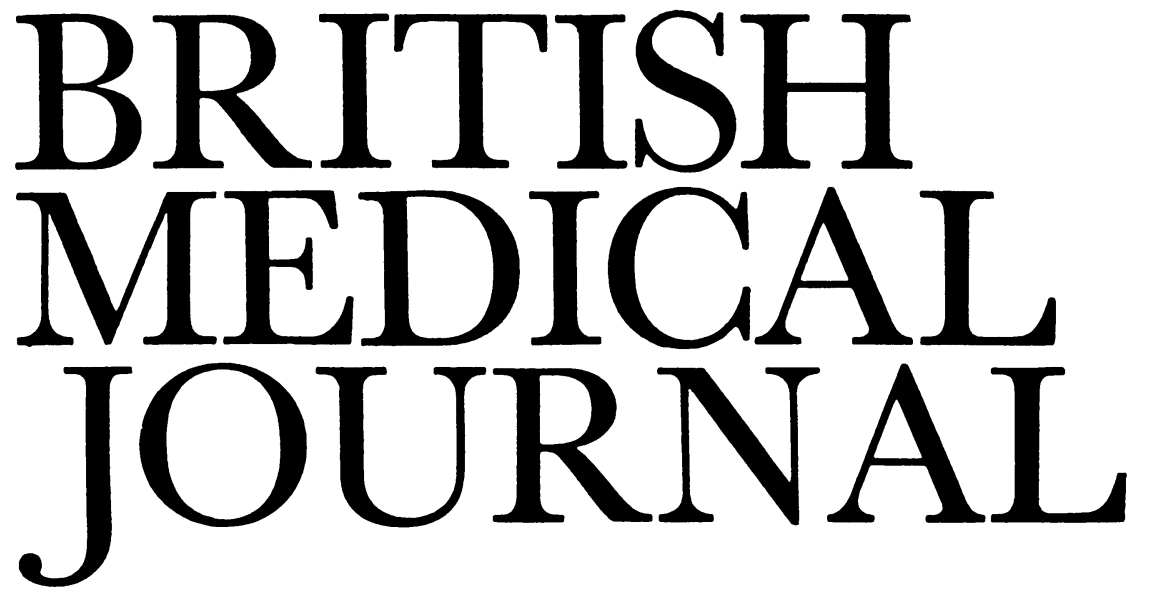

\title{
Impotence: science and sciencibility
}

The fault (or charm) of Jane Austen's Marianne Dashwood was that her sensibility was more obvious than her common sense. The fault (or charm) of those who bend clinical diagnosis into stepwise cascades-flow charts and algorithms -is that they may simplify the deductive process into a logical sequence which is neat but rarely accurate: sciencibility rather than science.

Conventional algorithms on impotence are based on a dichotomy: organic or psychogenic? Yet for most impotent men the aetiology is mixed; for, even if the initial erectile failure has organic causes, the reactions of the man and his partner are paramount in determining the outcome. ${ }^{1}$ 'Sadly, the conventional labelling of impotence as "organic" or "psychogenic" will also determine its management, patients in the former group perhaps receiving more sympathy and those in the latter being referred to the psychiatrists. Not only is the division into these mutually exclusive groups inappropriate in most cases; it is also based on inadequate grounds. We still know very little of the mechanisms of erection and of erectile failure.

The achievement of an erection depends on the subtle interaction of a complex series of neurovascular reflexes which culminate in blood flowing into the corpora cavernosa at roughly $100 \mathrm{ml}$ a minute and at arterial pressures approaching aortic systolic. Clearly blood flow will be impaired if arteriosclerotic changes have reduced the maximum arterial supply, but it may also be impaired by any neurological deficit. Reduced sensation in the genitalia would block the afferent limb of the excitatory reflex carried by the pudendal nerves_and reflex stimulation becomes increasingly important with increasing age.

Another cause of reduced blood flow may be disruption of the neurological control of vascular tone in the dorsal artery and the paired deep arteries. During tumescence venous outflow is obstructed (an erect penis cannot be collapsed with an inflated sphygmomanometer cuff). The importance of the parasympathetic nervi erigentes (derived from S2, 3, rarely 4; never all three) has long been recognised. Erection may also be induced by stimulation of the sympathetic erectile or inhibition of the sympathetic antierectile fibres which run together from the hypogastric plexus (T10-L2). Studies on men with traumatic lesions of the spinal cord or pelvis indicate that the parasympathetic system is essential for reflex erection but that psychogenic and sleep erection may be mediated by way of either pathway. ${ }^{3}$

Little is known of the neurotransmitters concerned. The sympathetic antierectile efferent is $\alpha$ noradrenergic, but the excitatory efferents are non-adrenergic and non-cholinergic. Vasoactive intestinal polypeptide almost certainly plays a part since it is present in the nerve fibres of the corpora cavernosa $^{4}{ }^{5}$ and is released into the dorsal vein of the erect penis in high concentration (though patients with vipomas do not suffer priapism). Other neuropeptides-somatostatin and substance $\mathrm{P}$-are present in high concentration, but their role is unknown. Dopaminergic systems may be concerned: the intravenous administration of some dopamine receptor stimulants results in erection. ${ }^{6}$ Neuropeptide $Y$ may effect venoconstriction (if it occurs, and if this is the mechanism by which venous outflow is blocked).

How these multiple and subtle pathways relate to the mechanisms of ejaculation and to the peripheral sensations which contribute to orgasm is unknown. Indeed, we might ask why so little is known about male genital function when so much more is known about the hypothalamus or the ovary. Might the explanation be centuries of male chauvinism? Because so little is known, it is as difficult to exclude organic factors contributing to erectile failure in "psychogenic" cases as it is wrong to ignore psychological factors in those which are "organic."

The linchpin of the algorithmic cascade is the use of a sleep laboratory to determine nocturnal penile tumescence associated with rapid eye movement sleep. A strain gauge determines the circumference of the penis, and in the best ordered and best funded centres the rigidity of any erection is also judged manually by an experienced observer. If nocturnal penile tumescence is absent, considerably reduced, or short lived, erectile failure is likely to have at least some organic component. The chances are increased if the failure is associated with clinical evidence of possible aetiological factors, including peripheral neuropathy, symptomatic autonomic neuropathy, peripheral vascular or cardiovascular disease, diabetes-especially with retinopathy-and exces- 
sive alcohol consumption. If nocturnal penile tumescence is normal the problem is usually assumed to be essentially psychogenic, but this interpretation should be made with caution since nocturnal penile tumescence tests only one aspect of the erectile mechanism. A man with early organic causes of erectile failure may achieve tumescence in some circumstances (such as sleep) but not in others. Such patchiness of early failure also undermines the traditional criteria by which psychogenic impotence may be suspected from a cursory history (the sort which any of us have time to take in a general clinic or surgery). Sudden onset, intermittence, preservation of morning erections, and ability to masturbate do not on their own exclude organic causes, just as an associated loss of libido is not a reliable indicator of endocrine disturbances.

So what can the average doctor do for the average man (2$7 \%$ of the population, increasing with age) who suffers with impotence? The first task is to define the nature of the complaint. Is the man really complaining of erectile failure, and is it he who is complaining? A brief history may suggest gross social and psychological derangement. A medical examination will establish the presence or otherwise of normal genitalia, neuropathy, and peripheral vascular disease. Drugs which may be incriminated (especially those used in the treatment of hypertension) may be changed. A blood sample should be taken for estimating concentrations of testosterone (which should not be low), luteinising hormone, and prolactin (which should not be high). A second interview should be arranged in which to review the results of the tests and at which time and privacy should be arranged for a more detailed conversation with the man-and if possible with his sexual partner. If this and subsequent interviews are undertaken by someone who is sympathetic and skilled, and who has the time, a great deal can be achieved. The counselling may be undertaken by a general practitioner, social worker, psychiatrist, psychologist, hospital doctor, nurse, family planning specialist, or sex therapist; the choice simply depends on who in the locality is the best person for that patient. Women are probably more sympathetic, although paradoxically it is to men doctors that impotent men usually turn for advice.

Documentation of nocturnal penile tumescence may be helpful, but few centres in Britain have the staff, space, or interest. The routine, sensible management of impotence (in an impoverished health service) has little place for pelvic arteriography, cavernosography, documentation of the penile brachial arterial pressure index, plethysmography, screening for autonomic neuropathy (that is, for cardiac denervation), and all the other high tech razzmatazz that make up most branches of most sciencible algorithms. These tests should be reserved for those institutes conducting the research which is still vitally needed. If nocturnal penile tumescence is absent or a substantial organic component is otherwise assumed further investigation should be directed only towards defining a treatable cause.

Once erectile failure is established as the dominant complaint and if counselling and education have been unable to allay fears or enable the couple to have sufficiently enhanced mutual sexual satisfaction other treatments should be considered. Firstly, there is no place for androgens, gonadotrophins, luteinising hormone releasing hormone, or dopamine receptor agonists in the absence of a defined endocrine abnormality - which is very rare in men who present with impotence. Secondly, there are non-surgical and surgical options which should probably be adopted more widely in
Britain than they are at present, though those who advocate implants must remember that all they do is to make the penis stand up. Very careful selection of patients is essential, but on the other hand high satisfaction rates have been reported.'

Two non-surgical techniques should be considered. Intracavernosal injection of $\alpha$ blocking agents such as thymoxamine, phentolamine, and phenoxybenzamine ${ }^{8}$ (as well as of papaverine, which is not an $\alpha$ blocker $^{9}$ ) undoubtedly works. These drugs will produce erections of good quality-but for unpredictable lengths of time, sometimes lasting many hours. To be socially acceptable the drug needs to be self administered. Appropriate facilities are becoming available - particularly in London, Paris, and New York. Careful monitoring of safety and efficacy is essential since priapism is an occasional (treatable ${ }^{10}$ ) complication, and intracavernosal fibrosis and distortion may occasionally occur with repeated in use (G S Brindley, unpublished observations). Possibly these $\vec{\circ}$ agents might be given with a transdermal high pressure spray (such as the ones marketed for insulin administration), but $\vec{\sigma}$ such subcutaneous administration may be less effective and more painful. The second non-surgical technique which has been advocated is penile engorgement by passive distension in a plastic tube from which the air is evacuated with a hand pump. The erection thereby achieved can be maintained with a rubber band and is of good quality and rapidly reversible. Although high satisfaction rates have been reported with this simple device, the erect penis tends to be cyanosed and numb and is flexible at its base; and ejaculation is blocked by the rubber band ( $P$ W Nadig, paper presented to XII Congress of the International Diabetes Federation, Madrid, 1985).

Such methods deserve to be more widely available for those in whom the complaint of impotence is truly synonymous with sexual dissatisfaction resulting from erectile failure. But they should be regarded as an additive to counselling not an alternative. Skilful counselling on its own may or may not restore potency, but it will help most men to understand the reasons for the failure and to achieve greater satisfaction (albeit with an erection which remains of poor quality). What is required is a little bit of science and a lot of sensitivity.

This paper is based on the proceedings of a symposium held at the City Hospital, Nottingham, under the auspices of the endocrine section of the Royal Society of Medicine. I am indebted to the contributors (Professor G S Brindley, Dr M Crowe, Mr M Dunn, Dr R G Long, and Dr I A Macdonald) as well as to Dr J Bancroft for his advice.

W J JEFFCOATE

Consultant Physician,

City Hospital,

Nottingham NG5 1PB

1 Bancroft J. Erectile impotence-psyche or soma? Int $\mathcal{f}$ Androl 1982;5:353-5.

2 Bancroft J, Wu F. Erectile impotence. Br Med f 1985;290:1566-8.

3 Brindley GS. Pathophysiology of erection and ejaculation. In: Whitfield HN, Hendry WF, eds. Textbook of genito-urinary surgery. Vol 2. Edinburgh: Churchill Livingstone, 1985:1083-94

4 Polak JM, Gu J, Mina S, Bloom SR. Vipergic nerves in the penis. Lancet 1981;ii:217-9.

$5 \mathrm{Gu}$ J, Polak JM, Probert L, et al. Peptidergic innervation of the human male genital tract. $f$ Urol 1983;130:386-91.

6 Wass JAH, Thorner MO, Jones A, MacLeod RM, Besser GM. Piribedil: hormonal profile of a parenterally administered dopamine agonist. Psychologie Médicale 1979;11B:263. 7 Whitehead ED, Leiter E. New frontiers in alloplastic genitourinary prostheses II. The surgical

8 Brindley GS. Cavernosal alpha blockade: a new technique for investigating and treating erectile impotence. Br f Psychiatry 1983;143:332-7.

9 Virag $R$, Virag $\mathrm{H}$. L'épreuve a la papavérine intracaverneuse dans l'étude de l'impuissance. $f \mathrm{Mal}$ Vasc 1983;8:293-5.

10 Brindley GS. New treatment for priapism. Lancet 1984;i:220. 